\title{
Online Education - a Reality of Our Times
}

\section{Cristina Ispas}




\title{
Online Education - a Reality of Our Times
}

\author{
Cristina Ispas ${ }^{a^{*}}$ \\ ${ }^{a}$ Educational Sciences Department, UBB University Studies Center from Reșița, Traian Vuia Square, No.1-4, Reșița, 320085, Romania \\ *Corresponding author: cristina.ispas@ubbcluj.ro
}

\section{Abstract}

Keywords:

online education; distance learning; technologies and means of communication; internet.

Zusammenfasung

\section{Schlüsselworte:}

Online-Bildung; Fernunterricht; Technologien und

Kommunikationsmittel; Internet.
The current context generated by the COVID 19 pandemic has determined, as far as education is concerned, a substantial orientation of didactic activities towards online education. On a par with teachers, the students and parents were confronted with the more or less familiar reality of online education. The process of adaptation to this type of education was not deprived of obstacles but was also a source of satisfactions on the professional and personal level. The present study highlights the characteristics of the online education, the need for online education in the COVID 19 pandemic context, as well as the advantages and disadvantages brought about by this type of education.

\section{Introduction}

Online education represents one of the most exciting forms of distance education. Understood as an alternative or complementary form of instruction, distance education must be designed and implemented so that it observes all the quality pedagogical standards, meant to lead towards the best results which can be obtained in the teaching-learning-evaluation activity. Distance education undeniably brings about a series of advantages and limits to the education field. Their analysis allows the continuous improvement of theories and practices in the field of online education.

\section{Theoretical foundation}

The literature offers numerous definitions attempting to clarify the meaning of online education as the current form of distance education. According to these definitions, distance education is understood as:

- "no more than a hodgepodge of ideas and practices taken from traditional classroom settings and imposed on learners who just happen to be separated physically from an instructor" (McIsaac \& Gunawardena, 1996, p.5),
- "Distance education is a form of education in which the participants in educational process - teacher and learners are physically separated and communicate by different means and at different times." (Kiryakova, 2009, p.29)

- "Distance education is teaching and planned learning in which teaching normally occurs in a different place from learning, requiring communication through technologies as well as special institutional organization" (Moore \& Kearsley, 2012, p.2).

The concept of "distance education" often used as a synonym for online education has been known and applied in practice for at least 200 years. This concept originates in the educational practices of the United States in the 1800's when the teachers and the students from the University of Chicago, who were in different locations, tried to stay connected with the study programs from a distance by mail. In those times, the teachers used printed materials and postal services for what was called mail education. (Mclsaac \& Gunawardena, 1996). 
The occurrence and development of the radio a century later facilitated the communication between people who were usually away from one another. Understanding the huge potential that the radio could offer, as back as 1921 the University in Salt Lake City made all the preparations to obtain the licence for broadcasting certain educational radio programmes. Distance education thus recorded a new stage in its evolution. Grace to the radio, the oral communication wins an important place within distance education. The emotion transmitted through paraverbal language accompanied the verbal message, being thus much easier to perceive or understand on the radio. Since its very appearance, the radio became extremely attractive and popular among population. It was not necessary any more to be able to read, write or stay near a radio set, you could simply listen to it. The success of these radio broadcasts was also amplified by the fact that the educational broadcasts were embedded or interbedded with short latest news, musical or entertainment shows etc.

Step by step, the radio started to broadcast to all the corners of the world and its messages were received by numerous listeners, facilitating people's access to information, education, culture.

In Romania, even since 1930, at the proposal of Professor PhD Dimitrie Gusti, the founding father of Romanian sociology, the Chairman of the Romanian Society of Radio Broadcasting at that time, they organised two radio conferences for the inferior and superior classes.

Neil Postman (1992) in his paper titled Technopoly: The surrender of culture to technology emphasises the fact that "it is not always clear, at least in the early stages of a technology's intrusion into a culture, who will gain most by it, and who will lose most." (p. 12)

Despite the time passed, even today there are numerous experiences where the radio is used for broadcasting certain educational contents. In the study The Return of Educational Radio? (2008), Sally D. Berman examines the way in which one of the traditional technologies of distance education, the radio, is used in the 21 st century for educational purposes in Asia, Africa and the Western world. The author suggests that the developed countries can learn from the developing countries today's use of the radio for educational purpose and that the radio deserves a higher attention as a means able to offer educational opportunities to the rural and isolated peoples throughout the world.

TV distance education had a great success due to the multiple opportunities offered by television which combines sound with image, succeeding in transmitting information, feelings, in influencing behaviours. In 1945 the University of Iowa obtained the first licence which allowed it to use television for educational purposes enabling it to open its gates to the public interested in knowledge, to the community. Thus, by means of television, there were offered broadcasts with general educational character on certain topics, on the one hand, and on the other hand they proposed broadcasts designed and realised taking into account the curriculum in force in the preuniversity and university system. A series of research surveys (.....) have shown that the results obtained by TV education are similar to those obtained in the traditional system when they are taken into account. By means of television, using the image and the sound we can reach all the components of education: intellectual, moral-civic, physical, artistic, aesthetic, etc. Likewise, television allowed the representation, in a very suggestive way, of some concepts, abstract ideas which explained with the help of moving images, accompanied by music have become more accessible to everyone.

Obviously, the practices in the educational space regarding the design and implementation of distance education existed long before the appearance of the internet. The development of distance means of communication, either by mail at the beginning and by radio and television or the computer technologies in the case of the latest generation, had a huge impact on people's lives, including education and the possibility of their use for educational purpose.

In the past 10 years, a series of concepts were used as synonyms for online education, such as: E-learning (or eLearning), multimedia learning, technologyenhanced learning (TEL), computer-based instruction (CBI), computer-based training (CBT), computerassisted instruction or computer-aided instruction (CAI), internet-based training (IBT), web-based training (WBT), virtual education.

Starting from the concepts that compose the phrase "online education", it can be intuitively defined as a way of developing an instructional-educational process by means of computer technology and communication on the internet. The researchers of Babeș-Bolyai University in Cluj-Napoca (Opre,. et al., 
2020) provide an alternative, more complex definition, according to which online education is a "didactic strategy (paradigm), ad-hoc designed for teachinglearning-evaluation based on informational technology, materialized by formative and evaluative sessions carried on online which alternates two types of instructional activities: synchronous and asynchronous."

The literature highlights that the development of online courses cannot be done overnight (https://www.informingscience.org/Publications/3502 ). A study conducted by the National Centre for Educational Statistics - NCES in the USA found that the main factors which the higher educational institutions in the USA to offer students online courses refer to the satisfaction of the students' demands for flexible programs (68\%), offering access to university studies also to students who otherwise could not have access (67\%), offering students more courses (46\%), aiming at increasing the students number at the same time (Parsad, Lewis, \& Tice, 2008).

The universities were among the first institutions interested in offering distance courses to their students, grasping the enormous opportunity that internet offers, in order to meet students' need for training, being disposed to invest in top technology in order to ensure the high quality standards for the design and development of the online courses.

The end of 2019, but especially 2020 would bring the most radical changes in the economic-socialcultural life worldwide by the emergence of the COVID-19 pandemic. Education, besides numerous other sectors of public life, had to be redefined and opened wide the gates of the online education. The development of informational and communication technologies offered teachers the opportunity to change their pedagogical approaches (Thamarana, 2016).

In the US, higher education, even before the emergence of the COVID-19 pandemic, online education represented the segment with the most rapid growth and the demand continues to grow (Seaman, Allen și Seaman, 2018; Ginder, Kelly-Reid și Mann, 2019). In the context of the COVID-19 pandemic, universities were the first who reacted positively, even from the beginning, to the new conditions and developed online courses for students, using various educational platforms for this purpose.

\section{Research methodology}

The purpose of this research consists in identification of the students' perception referring to the online education developed in the context of COVID 19 pandemic. In this direction we have aimed at the following specific objectives:

OS1: identifying students' opinions for continuing teaching activities in the form of online education;

OS2: emphasising some particular aspects regarding the way in which the online university education was achieved during the COVID -19 pandemic period, referring to the types of activities (synchronous and asynchronous), the duration and timetable of activities, the means (instruments) of online connection used by the students;

OS3: specifying the difficulties encountered in the online education by the students

The research was conducted in the period June 2020 - October 2020.

The aimed target group was made up of 200 students from 5 universities in Romania, from different programs of study. There were only 196 valid questionnaires (respectively 196 students, from the 200 initial ones, have answered the questions in the questionnaire; 4 students have sent incomplete questionnaires, which led to the rejection of these questionnaires from the research). The questionnaire was anonymously completed by 196 students participating in the research in the period March 2020October 2020. According to the gender, in the research, there were 124 female respondents $(63,27 \%$ of the total sample) and 72 male respondents $(36,73 \%$ of the total sample). Regarding the residence environment, 93 people (47, $45 \%$ of the total sample) live in the rural area, and 103 (52,55\% of the total sample) live in the urban area. The students participating in the research have ages from 20 to 49 years and regarding the year of study, the situation is as follows:

Table 1. The structure of research participants according to the year of study at the university

\begin{tabular}{lll}
\hline Year of studies & $\begin{array}{l}\text { No. of } \\
\text { students }\end{array}$ & $\%$ \\
\hline 1st year, BA/undergraduate level & 37 & $18.88 \%$ \\
2nd year, BA/undergraduate level & 48 & $24.49 \%$ \\
3rd year, BA/undergraduate level & 34 & $17.35 \%$
\end{tabular}


4th year of studies (or 1st year, master)

41

$20.92 \%$

5 th year of studies (or the 2nd year master

$18.37 \%$

Total

196

$100.00 \%$

The used investigation methods are: the study of documents and national and international specialised materials in the aimed field: inquiry-based questionnaire addressed to the students of 5 different universities in Romania.

The questionnaire contained 15 questions among which: 11 content questions (opinion questions), closed or semi-open and 3 factual/administrative questions (referring to age, gender, residence environment, field of study and year of study).

\section{Results}

The study of documents has highlighted the need to move to online education during the reference period. Likewise, some definitions for the online education were identified, a short history of the distance education was highlighted, we stated a series of synonyms used for the online education, as well as the theoretical registration regarding of the difficulties of online education.

The data obtained by means of the questionnaire were processed and interpreted quantitatively and qualitatively being presented in this study based on the some items followed during the research.

Item1. During the period 11 March 2020 October 2020, during the COVID-19 pandemic how did the university courses, which you attended, developed?
All the students participating in the research declare that the didactic activities they participated in during the period 11 March 2020 - October 2020 were developed exclusively online.

Item 2. How important is in your opinion to continue the didactic activity under the form of education online?

Table 2. Results obtained for the item no. 2

\begin{tabular}{lll}
\hline & $\begin{array}{l}\text { No. of } \\
\text { answers }\end{array}$ & $\%$ \\
\hline Very important & 156 & $79.59 \%$ \\
Important & 29 & $14.80 \%$ \\
Moderate Importance & 11 & $5.61 \%$ \\
Less important & 0 & $0.00 \%$ \\
Totally unimportant & 0 & $0.00 \%$ \\
Total & 196 & $100.00 \%$
\end{tabular}

For most of the students to continue studies during the Covid 19 pandemic is important $(14,80 \%$ of the total sample) and very important $(79,59 \%$ of the total sample). An essential role is played by the fact that universities have already had experience regarding the distance education, that is why they could offer, even from the beginning, to their students educational services of high quality, proving involvement, responsibility, flexibility.

Item 3. During the Covid-19 pandemic did you participate in online didactic activities on different platforms or social networks such as Teams, Zoom, Edmodo, Googlemeet, Skype, Facebook, Whatsapp etc.) achieved ...

Table 3. Results obtained for the item no. 3

\begin{tabular}{|c|c|c|c|c|c|c|}
\hline & Always & Mostly & Medium & Scarcely & Never & Total \\
\hline in synchronous way, with the possibility to intervene & 2 & 156 & 23 & 12 & 3 & 196 \\
\hline $\begin{array}{l}\text { (write questions in the chat for teachers/colleagues, to } \\
\text { take the floor etc?) }\end{array}$ & $1.02 \%$ & $79.59 \%$ & $11.73 \%$ & $6.12 \%$ & $1.53 \%$ & $100.00 \%$ \\
\hline \multirow{2}{*}{$\begin{array}{l}\text { in the synchronous way without the possibility to } \\
\text { intervene }\end{array}$} & 3 & 12 & 31 & 147 & 3 & 196 \\
\hline & $1.53 \%$ & $6.12 \%$ & $15.82 \%$ & $75.00 \%$ & $1.53 \%$ & $100.00 \%$ \\
\hline & & & & 18 & 178 & 196 \\
\hline in the asynchronous way (recorded audio-video lessons) & 0 & 0 & 0 & $9.18 \%$ & $90.82 \%$ & $100.00 \%$ \\
\hline in the asynchronous way (others, apart from the recorded & & & & & & \\
\hline audio-video lessons; for instance covering different & 166 & 21 & 6 & 3 & 0 & 196 \\
\hline $\begin{array}{l}\text { materials of the type: word, pdf., power-point, solving } \\
\text { various homework posted by the teachers? }\end{array}$ & $84.69 \%$ & $10.71 \%$ & $3.06 \%$ & $1.53 \%$ & $0.00 \%$ & $100.00 \%$ \\
\hline Others.Which? & 0 & 0 & 0 & 0 & 0 & 0 \\
\hline Total & $\begin{array}{l}171 \\
87.24 \%\end{array}$ & $\begin{array}{l}189 \\
96.43 \%\end{array}$ & $\begin{array}{l}60 \\
30.61 \%\end{array}$ & $\begin{array}{l}180 \\
91.84 \%\end{array}$ & $\begin{array}{l}184 \\
93.88 \%\end{array}$ & \\
\hline
\end{tabular}


From the data obtained we observe the fact that the synchronous activities prevailed, which allows the interaction of the student with the teachers and colleagues and the asynchronous activities, in which usually the emphasis is put on the individual study of the bibliographic references, on the achievement of assignments. In our opinion, it is a part of the didactic mastery the way in which the teacher guides learning, succeeding to involve students both in the synchronous activities and in the asynchronous ones. The facilities offered by the educational platforms has helped both students and teachers.

Item 4: What was the average time for the synchronous activities?

Table 4. Results obtained for the item no. 4

\begin{tabular}{lll}
\hline & $\begin{array}{l}\text { No. of } \\
\text { answers }\end{array}$ & $\%$ \\
\hline 1 hour or less & 78 & $39.80 \%$ \\
between 1 and 2 hours & 95 & $48.47 \%$ \\
more than 2 hours & 20 & $10.20 \%$ \\
$\begin{array}{l}\text { I did not participate in } \\
\text { synchronous lessons }\end{array}$ & 3 & $1.53 \%$ \\
Total & 196 & $100.00 \%$ \\
\hline
\end{tabular}

According to the students'evidence, most synchronous activities had a duration between 1 and 2 hours. The answer received from the students mostly reflects the number of hours foreseen in the curriculum for a subject of study, which is usually between one or two hours for each activity of course or seminar.

Item 5: Regarding the timetable of the online activities developed in synchronous way, were there any overlaps?

Table 5. Results obtained for the item no. 5

\begin{tabular}{lll}
\hline & $\begin{array}{l}\text { No. of } \\
\text { answers }\end{array}$ & $\%$ \\
\hline Never & 29 & $14.80 \%$ \\
Rarely & 117 & $59.69 \%$ \\
Sometimes & 23 & $11.73 \%$ \\
many times & 18 & $9.18 \%$ \\
Always & 9 & $4.59 \%$ \\
Total & 196 & $100.00 \%$ \\
\hline
\end{tabular}

Generally, the timetable of the online activities, with very few exceptions observes the timetable of face-to-face activities. Consequently, it is natural that the timetable overlaps are occasional and usually at the beginning of the semester and fewer during the semester. The data obtained from the interviewed students confirm this hypothesis, most of them stating that rarely (117 students, respectively $59,69 \%$ of the total sample) there are overlaps in the timetable, while $14,80 \%$ state that there were never overlaps in the timetable.

Item 6. In order to participate in the online didactic activities you usually used:

Table 6. Results obtained for the item no. 6

\begin{tabular}{|c|c|c|c|c|c|c|}
\hline & $\begin{array}{l}\text { Alwa } \\
\text { ys }\end{array}$ & $\begin{array}{l}\text { Mostl } \\
\mathrm{y}\end{array}$ & $\begin{array}{l}\text { Mediu } \\
\mathrm{m}\end{array}$ & $\begin{array}{l}\text { Scarce } \\
\text { ly }\end{array}$ & Never & Total \\
\hline \multirow[b]{2}{*}{$\begin{array}{l}\text { a } \\
\text { computer }\end{array}$} & 23 & 17 & 41 & 48.00 & 67 & 196 \\
\hline & $\begin{array}{l}11.73 \\
\%\end{array}$ & $8.67 \%$ & $\begin{array}{l}20.92 \\
\%\end{array}$ & $\begin{array}{l}24.49 \\
\%\end{array}$ & $\begin{array}{l}34.18 \\
\%\end{array}$ & $\begin{array}{l}100.00 \\
\%\end{array}$ \\
\hline \multirow[b]{2}{*}{ a laptop } & 62 & 45 & 33 & 37.00 & \multirow[b]{2}{*}{$\begin{array}{l}19 \\
9.69 \%\end{array}$} & 196 \\
\hline & $\begin{array}{l}31.63 \\
\%\end{array}$ & $\begin{array}{l}22.96 \\
\%\end{array}$ & $\begin{array}{l}16.84 \\
\%\end{array}$ & $\begin{array}{l}18.88 \\
\%\end{array}$ & & $\begin{array}{l}100.00 \\
\%\end{array}$ \\
\hline \multirow[b]{2}{*}{ a tablet } & 29 & 36 & 16 & 41.00 & 74 & 196 \\
\hline & $\begin{array}{l}14.80 \\
\%\end{array}$ & $\begin{array}{l}18.37 \\
\%\end{array}$ & $8.16 \%$ & $\begin{array}{l}20.92 \\
\%\end{array}$ & $\begin{array}{l}37.76 \\
\%\end{array}$ & $\begin{array}{l}100.00 \\
\%\end{array}$ \\
\hline \multirow{2}{*}{$\begin{array}{l}\text { a } \\
\text { smartpho } \\
\text { ne }\end{array}$} & 72 & 41 & 23 & 31.00 & 29 & 196 \\
\hline & $\begin{array}{l}36.73 \\
\%\end{array}$ & $\begin{array}{l}20.92 \\
\%\end{array}$ & $\begin{array}{l}11.73 \\
\%\end{array}$ & $\begin{array}{l}15.82 \\
\%\end{array}$ & $\begin{array}{l}14.80 \\
\%\end{array}$ & $\begin{array}{l}100.00 \\
\%\end{array}$ \\
\hline \multirow{2}{*}{$\begin{array}{l}\text { Others. } \\
\text { Which? }\end{array}$} & 0 & 0 & 0 & 0 & 0 & 0 \\
\hline & $0.00 \%$ & $0.00 \%$ & $0.00 \%$ & $0.00 \%$ & $0.00 \%$ & $0.00 \%$ \\
\hline \multirow[b]{2}{*}{ Total } & 186 & 139 & 113 & 157 & 189 & 196 \\
\hline & $\begin{array}{l}94.90 \\
\%\end{array}$ & & $\begin{array}{l}57.65 \\
\%\end{array}$ & $\begin{array}{l}80.10 \\
\%\end{array}$ & $\begin{array}{l}96.43 \\
\%\end{array}$ & $\begin{array}{l}100.00 \\
\%\end{array}$ \\
\hline
\end{tabular}

From the data analysis we observe the students' preference for the mobile means of communication, especially smartphone and laptop. Obviously, each of these means have their technical characteristics which help or limit the development of the didactic act by their means.

According to the evidence of the students participating in the research, most of the synchronous activities use the phone which allows rapidly the connection form wherever they are, but for the asynchronous activities (especially when they filled in hangouts or wrote essays, abstracts etc) they prefer the laptop or the computer. 
"Due to the pandemic crisis there has been a huge, disruptive shift from existing educational system to online education system" (Soni, 2020).

Any didactic act supposes to face some challenges, to answer some difficulties. From this perspective the interviewed students have offered the following answers:

Item 7. What difficulties did you encounter in the online courses during the Covid 19 pandemic period?

Table 7. Results obtained for the item no. 7

\begin{tabular}{lll}
\hline & $\begin{array}{l}\text { No. of } \\
\text { answers }\end{array}$ & $\%$ \\
\hline I have not encountered difficulties & 56 & $28.57 \%$
\end{tabular}

I have not encountered difficulties

56

$28.57 \%$

Difficulties connected to the acquainting to the platform on which the didactic activities were done;

Difficulties in the creation of an account and logging on the platform;

Difficulties connected to the operation

of the

computer/laptop/tablet/smartphone;

Difficulties connected to the internet operation;

Difficulties connected to the operation of the used platform on the development of didactic activities;

Difficulties connected to the timetable;

Personal difficulties regarding the participation in the online courses (socio-medical problems, tiredness, unability to concentrate during the course, job etc.);

$17.86 \%$

Others. Which?
$0.00 \%$

If 56 students $(28,57 \%$ of the total sample $)$ consider that they did not meet difficulties regarding the development of online didactic activities, the others identify in average 3-4 problems they met and which they should face. It is true that when the problems met are perceived as having a high degree of difficulty or they are very easy they tend to generate demotivation among the students, leading to the installation of hopelessness, despair, apathy or even indifference. This is why it is important to have the support of the teachers and their colleagues in solving some inherent problems.

\section{Discussions and conclusions}

The spreading of the coronavirus infection has determined teachers and students to rapidly adapt to the new situation, in which school continues even outside the school walls and traditional classrooms, using online knowledge and instruments accessible to everyone. The experience to develop educational activities using digital resources and instruments prevailingly existed in the university educational system but in a net inferior scale are to be found in the pre-university system even during the period before the start of the COVID -19 pandemic. The exclusive use in the design and implementation of didactic activities of digital resources and instruments during the coronavirus pandemic has constituted the novelty element but also of high pressure on the educational system, revealing vulnerable aspects connected to the school infra-structure, of digital endowment that students and teachers, of the discrepancies existing between schools and families in the urban and rural area, highlighting the difficulties concerning the implementation of online education, but also the solutions found in order to surpass them, true "challenges that teachers, students, parents and decision-makers try to face in the rapid rhythm in which they appear, manifesting in variable proportions, the availability, interest, pedagogical mastery, inventiveness". (Botnariuc et al, 2020, p. 8)

\section{Authors note:}

Cristina Ispas is a Ph.D. University Lecturer at the Faculty of Psychology and Sciences of Education, in Educational Sciences Department (Babeş Bolyai University, Cluj Napoca, Romania). Fields of interest in research: Student Class Management, Pedagogy for Primary and Preschool Education, Teaching Career Management, Inclusive Education.

\section{References}

Berman, S. (June 2008). Technical Report. The Return of Educational Radio?, Available online at: http://www.irrodl.org/index.php/irrodl/article/view/563 $/ 1038$ (accessed at 14.10.2020).

Ginder, S., Kelly-Reid, J., \& Mann, F. (2019). Enrollment and employees in postsecondary institutions, fall 2017; and financial statistics and academic libraries, fall 2017. Washington, D.C.: U.S. Department of Education. Available online at: https://nces.ed.gov/ pubs2019/2019021REV.pdf. (accessed at 15.10.2020).

Kiryakova, G. (2009). Review of distance education, Trakia Journal of Sciences, Vol. 7, No. 3, pp 29-34, Available online 
https://www.researchgate.net/publication/279448170_ Review_of_distance_education (accessed at 15.09.2020).

McIsaac, M. S., \& Gunawardena, C. N. (1996). Handbook of research for educational communications and technology: A project of the association for educational communications and technology. New York, NY: Simon \& Schuster Macmillan.

Parsad, B., Lewis, L., \& Tice, P. (2008). Distance education at degree-granting postsecondary institutions: 2006-07, National Center for Education Statistics Institute of Education Sciences, Available online at: https://nces.ed.gov/pubs2009/2009044.pdf (accessed at 20.09.2020).

Postman, N. (1992). Technopoly: The surrender of culture to technology. New York: Vintage books.

Seaman, J., Allen, I. E., \& Seaman, J. (2018). Grade increase: tracking distance education in the United States. Babson Survey Research Group. Available online at: https://onlinelearningsurvey.com/ reports/gradeincrease.pdf. (accessed at 18.08.2020).

Soni, V. D. (2020). Global Impact of E-learning during COVID 19, Available online at: https://papers.ssrn.com/sol3/papers.cfm?abstract_id=36 30073 (accessed at 12.10.2020).

Thamarana, S. (2016). Role of E-learning and Virtual Learning Environment in English language learning, Available online at: https://www.researchgate.net/publication/305913807_ Role_of_Elearning_and_Virtual_Learning_Environment_in_Engli sh_language_learning (accessed at 25.09.2020).

Academia Română (2020) Punct de vedere privind educația on-line Available at: https://academiaromana.ro/mediaAR/pctVedereAR/202 0/d0728-Punct_de_vedere_Educatia -online_si_educatia_in_clasa.pdf (accessed at 16.10.2020). 